\title{
EDWARD SAID Y LA FIGURA DEL INTELECTUAL AMATEUR
}

\section{David VIÑAS PIQUER}

Universidad de Barcelona

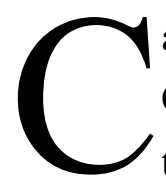

arlos Reynoso marca una clara diferencia entre dos modalidades dentro de los Estudios Culturales: «por un lado está el corpus canónico de Williams-Thompson-Hoggart et al. y los textos que prolongan la idea original de estudios de la cultura popular inglesa; por el otro se agrupa lo que en general pasa hoy por Estudios Culturales lato sensu, y que a pesar de las infaltables referencias al canon no tiene mucho que ver con él en términos de método, política, reflexividad y elaboración conceptual» (2000: 22). No es difícil advertir que esta diferencia quiere establecer una clara jerarquía entre la indudable calidad de las obras de Raymond Williams, E.P.Thompson, Richard Hoggart y Stuart Hall, considerados los fundadores (los founding fathers) de los Estudios Culturales, y las obras de muchos de los que vinieron detrás siguiendo sus pasos. Entre estos últimos, sin embargo, se encuentran nombres como los de Edward Said, Homi Bhabha y Chakravorty Spivak, máximos representantes de la teoría postcolonial, que ha sido considerada «el último y más interesante desarrollo de los Estudios Culturales» (Grüber, 1998: 20). En esencia, esta teoría intenta rastrear y sacar a la luz vestigios de colonialismo todavía detectables en los discursos y las prácticas del mundo postcolonial. La demostración suele realizarse con categorías de análisis tomadas de autores como Foucault, Derrida, Lacan o De Man, y se consiguen con ellas grandes logros en la crítica cultural e ideológica. Esto prueba que, después de los padres fundadores, también han aparecido obras de gran calidad en el ámbito de los estudios culturales.

El caso de Said es uno de los más interesantes. Su obra abraza algunos de los temas frecuentes en el campo de los estudios culturales (como la identidad cultural y nacional o el colonialismo y el postcolonialismo), pero también temas más clásicos, relacionados, por ejemplo, con la crítica literaria (Beginnings y El mundo, el texto y el crítico son ensayos fundamentales en este sentido), o con la reflexión sobre la figura del intelectual y su función en la sociedad. En este último caso destacan textos como Representaciones del intelectual, que recoge una serie de conferencias dictadas en 1993 (en el marco de las Reith Lectures de la BBC), y «La función pública de los escritores e intelectuales», que es bastante posterior. En el segundo de estos textos, Said dice que las importantes transformaciones políticas y económicas que se han producido desde que dictó las conferencias de 1993 le obligan a 
modificar su punto de vista y añadir algunas cuestiones; sin embargo, una lectura atenta de ambos trabajos nos permite advertir en ellos una evidente coherencia de pensamiento que se manifiesta en la presencia de unas mismas ideas esenciales sobre la intelectualidad.

Al investigar sobre el sentido moderno de la intelectualidad, y sobre el origen mismo del sustantivo «intelectual», E. Inman Fox recordaba la actitud que hacia los años 1830-40 ostentó el círculo de escritores y artistas que conformaban la denominada intelligetsia rusa. Se trató fundamentalmente de «una actitud crítica e independiente frente al gobierno y la sociedad de su país» (1988: 14) y en ella residía ya, por tanto, la idea principal que modernamente se asocia a la figura del intelectual como alguien que, descontento con el orden socio-político establecido, esgrime sus opiniones personales en busca de una determinada reacción social. Al parecer, ni la palabra intelligentsia ni el concepto al que remite llegaron a trasladarse desde Rusia a otros países europeos hasta finales del siglo XIX, momento en el que el célebre «affaire Dreyfus» provocó la organización de un grupo de profesionales franceses que intentaron influir con diversas publicaciones en la opinión pública.

Como es de sobra conocido, el primer paso lo dio Émile Zola con la publicación de «J'accuse», la carta abierta dirigida al presidente de la Tercera República que apareció en el periódico parisiense L'Aurore el 13 de enero de 1898.Desde 1897 se sabía que el proceso al capitán francés, de origen judío, Alfred Dreyfus, condenado por la supuesta venta de ciertos secretos militares a Alemania, había sido manipulado y Zola decidió denunciar públicamente la injusticia acusando a diversas autoridades militares de ser los responsables de la manipulación. Como era de prever, Zola sufrió una rigurosa persecución legal por haber provocado semejante grado de agitación social y tuvo que escapar del país, pero sus acusaciones no fueron infructuosas: finalmente, Dreyfus fue rehabilitado. No es extraño entonces que la carta de Zola haya sido considerada «auténtica acta de nacimiento de la figura del intelectual» (Blasco, 1998: 7).

Sin duda, el gesto valiente del novelista francés, al que pronto se sumaron gestos de otros autores, contribuyó de forma decisiva a que la palabra «intelectual» pasara a ser usada para etiquetar a un grupo heterogéneo de profesionales que, por encima de divergencias ideológicas y gremiales, habían demostrado tener algo muy importante en común: la voluntad de manifestarse de forma colectiva ante lo que se consideraba una injusta arbitrariedad del Estado. Desde ese momento, al intelectual se le ha exigido siempre una participación activa en la actualidad del mundo, se le ha exigido un compromiso con su sociedad y que no caiga en lo que Sartre llamaba «la tentación de la irresponsabilidad». También se ha asociado a la figura del intelectual la independencia política y económica de su pensamiento, pues esta es la máxima garantía de credibilidad y, en definitiva, de autoridad. Edward Said asegura en Representaciones del intelectual que la «misión principal» de los intelectuales es, precisamente, «revestir de autoridad las iniciativas en que participan» (1996: 16), y difícilmente se puede lograr esto cuando se dan casos de servilismo o de prostitución de la inteligencia, como ya demostró Gramsci con su idea del intelectual orgánico (opuesto al intelectual disidente). Con toda contundencia afirma Said que el intelectual tiene que defender sus ideas independientemente «del partido en que milite» y 
también independientemente «de su procedencia nacional y de sus lealtades primigenias» (1996: 14). La búsqueda de una independencia frente a cualquier presión, llega a decir Said, es «el principal deber del intelectual» (1996: 17).

Esta idea que aparece como un leitmotiv en las conferencias de 1993 reaparece en «La función pública de los escritores e intelectuales», justo cuando Said afirma que actualmente «resulta muy difícil concebir durante más de uno o dos segundos la sola idea de que un intelectual no se vea empujado por una cierta pasión por un cargo o por la ambición de hacerse oír por alguien que ocupe un puesto de poder», ya que «los beneficios económicos y la fama son estímulos muy poderosos» (2006: 149). Frente a estas tentaciones, Said se pone a sí mismo como ejemplo de resistencia a la seducción del poder. Así, cada vez que en una entrevista le han preguntado sobre lo que pensaba que debía hacer el gobierno en una situación determinada, él asegura haberse negado a entrar en ese juego: «para mí ha sido una cuestión de principios no responder siempre a esa pregunta» (2006: 150). Su silencio en esos momentos era la máxima garantía de no poner su pensamiento al servicio de los intereses del poder y evitar así mantener con él una relación orgánica. No quiere decir esto, por supuesto, que el intelectual no deba inmiscuirse en cuestiones políticas, entre otras cosas porque, como dice Said, «la política es omnipresente; no hay huida posible a los reinos del arte y del pensamiento puros o, si se nos permite decirlo, al reino de la objetividad desinteresada o de la teoría trascendental» (1996: 38). De lo que se trata, entonces, es de entender que, al asumir el deber de interesarse por asuntos políticos, el intelectual tiene que comportarse como intelectual, y no como político. Es interesante recordar lo que escribió Francisco Ayala al respecto, cuando le preocupaba marcar la diferencia entre ambas posiciones: «Una de las propensiones casi invencibles del intelectual es la que tiende a proclamar sin disimulo aquello que considera ser verdad, mientras que el político vigila sus expresiones y atiende a la oportunidad con una astucia casi instintiva, cultivando el arte de hablar a tiempo y de callar a tiempo» (1989: 570).

Cuando por algún motivo un partido político se encuentra en condiciones de exigir a un intelectual lealtad a la línea partidista, algo se resiente, asegura Said, «en la vocación del intelectual» (1996: 77). De modo que, si se adivina la sombra de un grupo de presión detrás de lo que defiende un intelectual, el contenido de su discurso, sea cual sea, carecerá ya del mérito de haber nacido desde una visión independiente, autónoma y, sobre todo, crítica.

Y es que, además de la independencia, el espíritu crítico suele ser considerado un requisito básico de la condición de intelectual. Este espíritu se concreta en un examen desprejuiciado de toda situación considerada injusta o sostenida sobre principios irracionales y que vaya en contra de ciertos valores fundamentales. «La responsabilidad de los intelectuales - escribía Noam Chomsky en un ensayo de 1968 - consiste en decir la verdad y en denunciar la mentira» (1969: 35). En la misma línea se sitúa Said, que tantas veces cita a Chomsky como ejemplo de intelectual esforzado, cuando se refiere a las «visiones desenmascaradoras o alternativas en las que, por todos los medios a su alcance, el intelectual trata de decir la verdad» (1996: 39). Con estas palabras se señala la necesidad de poner entre paréntesis, como diría Husserl, cualquier prejuicio, cualquier opinión acríticamente aceptada. Gracias a este gesto, el intelectual puede entrar en conflicto con cualquier verdad que se presente como incuestionable y 
proceder a examinarla con cuidado para desmontarla y sacar a la luz su falsedad. Esto es especialmente necesario cuando la verdad oficial sirve para mantener alguna situación injusta. Es entonces cuando la voz del intelectual tiene que hacerse escuchar y mostrarse discrepante, fastidiosa, incómoda. Said habla en este sentido del intelectual como «francotirador», como alguien «que se esfuerza por decirle la verdad al poder» (1996: 17). Ahora ya sabemos de qué verdad se trata: de la que siempre está en la otra cara de la moneda, la que no se ve porque ha sido deliberadamente (interesadamente) ocultada.

Consecuente con este planteamiento, Said demuestra en libros como Orientalismo o Cultura e imperialismo que Oriente es una invención hecha a la medida de Occidente, una manipulación de la que ha surgido una imagen del otro totalmente artificial, falsa, un estereotipo que habría que rechazar por ofensivo. Frederic Jameson decía que la cultura «debe verse siempre como un vehículo o un medio por el cual se negocia la relación entre los grupos», y que, en esencia, las relaciones entre dos grupos «se reducen a las primordiales de envidia y odio» (1998: 103-104). Es decir, que un grupo puede sentir envidia del otro e intentar apropiarse de su cultura, o bien puede sentir odio hacia el otro grupo y esgrimir ese odio como defensa de las fronteras de su propio grupo. Algo de esto ve, y denuncia, Said en la relación entre Occidente y Oriente. Ya sea por envidia, por odio, por miedo o por desinterés, el caso es que la dominación occidental del denominado Tercer Mundo da como resultado una imagen estereotipada de Oriente como algo exótico, un espacio desconocido que quiere ser occidentalizado, que quiere adoptar la cultura, mucho más avanzada, de los occidentales. La manipulación es notoria y muestra cómo la relación con el otro se entiende sólo como domesticación de lo otro. Cultura e imperialismo nace con la idea de dar voz a Oriente y mostrar cuál fue en realidad la respuesta que se dio a la dominación occidental, una respuesta que, no lo olvidemos, culminaría en un gran movimiento de descolonización y que vendría a probar que lo que hubo no fue una aceptación resignada y hasta simpática de la cultura dominante, sino una reacción de resistencia cultural (Said, 1996a: 12). Como a Said le interesa poner de manifiesto la complejidad de la historia, y no simplificarla, reconoce que esa resistencia no fue siempre ejemplar porque «no consiguió impedir la aparición de movimientos nacionalistas represivos sustitutivos de los regímenes coloniales», pero cree que puede aprenderse mucho de estos hechos históricos para poder construir alguna vez «campos de coexistencia en lugar de campos de batalla», que debería ser para él uno de los objetivos del intelectual (2006: 168). Aparte de estas últimas reflexiones, que se encuentran ya en «La función pública de los escritores e intelectuales», con trabajos como Orientalismo y Cultura e imperialismo Said muestra el proceso de construcción de una identidad cultural y de alguna manera nos invita a ponernos en guardia frente a cualquier estereotipo. Aquí tenemos, pues, una aplicación práctica, asumida en primera persona, de lo que en un nivel teórico exige Said al intelectual: «Una de las tareas del intelectual consiste en el esfuerzo por romper los estereotipos y las categorías reduccionistas que tan claramente limitan el pensamiento y la comunicación humanos» (1996: 12).

Las preocupaciones de Said acerca de la función de la esencia de la intelectualidad le lleva a hablar no sólo de los intelectuales orgánicos de los que hablaba Gramsci (al servicio de clases o empresas que quieren aumentar su poder), sino también del célebre libro de Julien Benda, La trahison 
de clers, tradicionalmente considerado, como reconoce el propio Said, «un ataque feroz contra los intelectuales que renuncian a su vocación y comprometen sus principios» (1996: 24). Del libro de Benda, Said destaca la utilización de un concepto como el de «clérigo» o «clerecía» (ya reflejado en el título) para referirse a los intelectuales auténticos como personas que se comprometen con grandes conceptos, como la verdad y la justicia, y no con intereses y objetivos prácticos. Esta idea explica que autores como Francisco Ayala hayan utilizado también expresiones como «papel sacerdotal»o «verdadero sacerdocio laico» para referirse a la función orientadora que los intelectuales tienen que desempeñar en la sociedad. También Gabriel Zaid hablaba en este sentido del papel de los intelectuales «como una especie de clerecía civil» (1991: 100). Said se acerca mucho a estos planteamientos cuando, enlazando con los argumentos de Julien Benda, afirma que «hemos de discernir la figura del intelectual como un ser aparte, alguien capaz de decirle la verdad al poder, un individuo duro, elocuente, inmensamente valiente y aguerrido para quien ningún poder humano es demasiado grande e imponente como para no criticarlo y censurarlo con toda intención» (1996: 27). Decirle la verdad al poder: reaparece ahí la idea del intelectual como francotirador y «perturbador del status quo» (1996: 12), alguien capaz de desenmascarar las representaciones o relatos oficiales y ofrecer alternativas.

En «La función pública de los escritores e intelectuales», Said destaca el hecho de que, a finales del siglo XX, cada vez más los escritores han ido participando de los rasgos del intelectual, lo que recuerda, por cierto, que ya Sartre había planteado sus ideas sobre la literatura comprometida dando por supuesto que los escritores eran intelectuales, y este detalle no se le pasó por alto a Said en las conferencias de 1993: «Sartre utiliza el término escritor con preferencia al de intelectual, aunque es evidente que está hablando del papel del intelectual en la sociedad»(1996: 83). Siguiendo la estela de sartre, pues, afirma Said: «No es necesario mantener la distinción básica entre intelectuales y escritores puesto que, en la medida en que ambos actúan en la nueva esfera pública dominada por la globalización, [...] su función pública como escritores e intelectuales puede analizarse de forma conjunta» (2006: 155). Desempeñar esa función pública, que en esencia será la función de actuar como francotiradores contra el poder, resulta especialmente necesario, claro, cuando se detecta algún tipo de abuso por parte del poderoso, ya se trate de gobiernos o de instituciones. El intelectual tiene que salir entonces, afirma Said, en defensa de los desvalidos y «representar a todas esas personas y cuestiones que por rutina quedan en el olvido o se mantienen en secreto» (1996: 30). Es fácil acordarse en este punto de las ideas de Gramsci sobre la subalternidad.

Gramsci estableció la categoría de «subalterno» para referirse a una posición de subordinación dentro de una jerarquía basada en la dominación y la submisión, y esta categoría se conjugó con la de clase social, de base marxista, para llegar a la conclusión de que las clases subalternas están siempre fragmentadas, divididas, por culpa de la subordinación al poder de las clases dominantes. De esta manera, su identidad no llega a consolidarse y por eso ya decía Marx que las clases subalternas no podían representarse a sí mismas y necesitaban de alguien que lo hiciera por ellas. Gramsci profundizó en esta idea introduciendo el concepto de «hegemonía», con el cual quería ilustrar cómo la clase dominante conseguía que sus intereses fuesen reconocidos también como propios por parte de las 
clases subalternas, lo que lógicamente dificulta la construcción identitaria de cualquier grupo que se encuentre en esa posición de subalternidad. Por eso es preciso que alguien asuma la responsabilidad de representar a quien no sabe o no puede representarse, y ahí es donde Said cree que tiene que entrar en juego la figura del intelectual para convertirse en el portavoz de los subalternos. Pero si la representación no se hace desde dentro de las clases subalternas, sino desde afuera, una cierta asimetría resulta inevitable. No hay un lugar de enunciación que no lo sea, así que sólo se puede hablar en nombre de otros desde la propia posición y mostrar lo que desde ella se ve. Obviamente, esto condiciona lo que se acaba diciendo. En este contexto cobra todo su sentido la pregunta que se hacía Gayatri Spivak: «Can the Subaltern Speak? (¿Pueden hablar los subalternos?)». Spivak quería llamar la atención sobre el hecho de que la imposibilidad de hablar del subalterno no es física, sino ideológica porque, aunque hablara, nadie le escucharía, pues para ser escuchado hay que hablar desde una posición oficialmente reconocida, con una cierta validez institucional. Por otra parte, al no tener una conciencia clara de su identidad, el subalterno probablemente hablaría repitiendo la ideología oficial en su entorno. Hable o no hable, pues, el subalterno está condenado al silencio. Y si un intelectual habla por él, aprovechando su prestigio para causar algún efecto en el espacio social, en realidad no cambia mucho la situación porque, si no habla directamente el subalterno, seguimos ante una forma de silenciamiento. El intelectual sólo hace de ventrílocuo, y ya decía Spivak que el ventriloquismo era la herramienta típica del intelectual de izquierdas, que no se daba cuenta del terrible error epistemológico que supone explicar y pensar a los otros desde afuera, desde otra posición y a través de un modelo de pensamiento que no les es propio. De este modo, Spivak denunciaba no sólo la falsa transparencia del intelectual, sino también lo mismo que había denunciado Said en Orientalismo: la construcción artificial del otro.

Pretender explicar al otro desde un esquema de pensamiento que no le corresponde es también una muestra evidente de algo que ya Gramsci intuyó: que los intelectuales hablarían cada vez un lenguaje más especializado y serían comprendidos sólo por miembros del mismo campo profesional. Curiosamente, cuando Said habla del «discurso intelectual académico» aprovecha para denunciar su «hermetismo»y su «falta de combatividad «(2006: 151). Describir al otro desde el propio lenguaje especializado no puede ser, en efecto, más que una maniobra totalmente artificial y, desde el punto de vista combativo, muy poco eficaz. Al reflexionar sobre esta cuestión, Said recuerda que Michel Foucault habló del intelectual específico para referirse a quien «trabajando dentro de una disciplina determinada es capaz de utilizar su competencia en cualquier otro campo» (1996: 28) y le parece advertir un peligro en esta figura. A saber: «que el intelectual se limite a ser un profesional más» (1996: 29). Dicho con otras palabras: a Said le preocupa que el intelectual sea absorbido por las industrias del conocimiento y ponga su competencia específica (de intelectual específico) al servicio de los intereses de estas industrias cuando, en realidad, debería estar al servicio de la sociedad, defendiendo principios universales como la libertad y la justicia, cosa que puede hacerse mejor desde la posición del amateur que del profesional (1996: 31 y 94). Foucault quería ilustrar la evolución que se había producido en la figura del intelectual, desde el intelectual clásico o universal (con el modelo paradigmático de Sartre) 
al intelectual específico, para destacar que los intelectuales ya no tenían que cargar con el peso de la universalidad, la verdad y la representatividad, es decir, ya no tenían que pronunciarse sobre grandes cuestiones del mundo para desvelar la verdad enmascarada por los aparatos ideológicos y hablar por los oprimidos, sino que su función había cambiado y tenían que limitarse a desarrollar su actividad «mediante intervenciones concretas en problemas concretos, como un especialista que presta su conocimiento específico para contribuir a una causa» (Fortanet, 2010: 218). De este modo, la tarea del intelectual adquiere un nuevo sentido: tiene que limitarse a realizar diagnósticos sobre situaciones concretas para que se entienda mejor el presente y pueda ser visto en toda su complejidad, sin que esto implique apuntar hacia algún ideal de futuro, hacia alguna utopía. No se trata, como quería Richard Rorty, de reformar el presente para lograr un futuro mejor, pues el intelectual específico sólo diagnostica, y aunque su diagnóstico contiene una evidente subversión, y hasta una provocación, no se llega a dar el paso hacia la actuación en la esfera pública. Quienes tienen que dar el paso son los oprimidos, los subalternos, en nombre de quienes el intelectual específico no habla porque les pasa directamente la palabra, para que tengan voz (resultaba indigno hablar por ellos, como hacía el intelectual clásico) y para que protagonicen su propia lucha, a la que el intelectual específico sólo contribuirá señalando, gracias a sus competencias específicas, las zonas estratégicas donde conviente plantear la resistencia.

La idea de un intelectual que no sale del presente y que interviene en la realidad social sólo a través de un análisis especializado no parece seducir demasiado a Said, que significativamente apenas entra a valorar los argumentos de Foucault. Y por otra parte, su convencimiento de que lo que tienen que hacer los intelectuales «no sólo es definir la situación, sino también discernir las posibilidades de intervención activa» lo aparta de los planteamientos foucaultianos (2006: 167). Su apuesta se parece más al modelo encarnado por Noam Chomsky, a quien pone como ejemplo de académico capaz de salir de su especialidad para interesarse por otras muchas cuestiones que afectan al mundo en que vive y para intentar valorarlas desde una postura crítica que ofrezca alguna esperanza de cambio. Chomsky no era un experto en conflictos bélicos y, sin embargo, Said cree que sus reflexiones sobre la guerra de Vietnam fueron mucho más interesantes que la de la mayoría de expertos que trataron el tema. Otra cosa es que los especialistas en política exterior no quisieran escucharlo y lo vieran como un profano en la materia. Ahí tenemos, pues, el caso de un especialista en una disciplina académica concreta (la lingüística) que no actúa como intelectual específico, sino que, liberándose de la «presión del profesionalismo», como le gusta decir a Said, se ocupa de cuestiones, y en el fondo de ideas y valores, que van mucho más allá de los límites de su profesión. «Negarse a quedar atrapado en una especialidad» debería ser para Said un requisito fundamental para acceder a la condición de intelectual (1996: 84). Hay que tener en cuenta que Said plantea estas reflexiones en una época en la que se rinde culto a la especialización, una época en la que parece que cada vez haya que saber más... sobre menos. Recordando lo que escribió Russel Jacoby en Los últimos intelectuales, Said ofrece esta imagen triste de la situación promovida por la moda de la especialización: «El resultado de todo esto es que el 
intelectual de hoy tiende a ser un profesor de literatura herméticamene encerrado en sí mismo, con ingresos fijos y seguros y apenas interesado en abordar el mundo exterior al aula» (1996: 79-80).

El diagnóstico empeora cuando Said dice que este profesor solipsista escribe «en una prosa esotérica y bárbara puesta principalmente al servicio de la promoción académica y no del cambio social» (1996: 80). La denuncia del efecto pernicioso provocado por el culto a la especialización había sido ya hecha por Said en la introducción a El mundo, el texto y el crítico, donde tras hablar de las distintas formas de hacer crítica literaria y presentarlas como muestras de «una división del trabajo intelectual muy precisa», confesaba su intención de ejercer de crítico literario sin ajustarse a ninguna de ellas, sino yendo más allá de todas, alejándose de los especialistas e instalándose en una conciencia crítica que se acercara considerablemente a la posición que deberían mantener los intelectuales (2004: 12). La connexión que establece entre crítico literario e intelectual queda clara en esta declaración que hace casi al final de su introducción: «Porque en lo esencial -y aquí seré explícito- la crítica debe pensar en sí misma como algo que realza la vida y está constitutivamente opuesto a toda forma de tiranía, dominación y abuso; sus objetivos sociales son el conocimiento no coercitivo producido en interés de la libertad humana» (2004: 47).

Como vemos, con toda naturalidad Said anula cualquier frontera entre el oficio de crítico y el compromiso del intelectual, y esta es su manera de combatir la especialización en cualquiera de los dos campos. La descripción que hace del profesor solipsista va en ese mismo sentido. El intelectual «modo Chomsky», que es el que a Said le atrae, representa todo lo contrario. Representa al intelectual que se compromete «con un amplísimo abanico de asuntos» que afectan a la sociedad (1996: 82). Pero, como es lógico, no puede existir un campo de estudio especializado que sea el mundo entero. Nadie puede ser especialista en todo, de manera que el intelectual en el que piensa Said por fuerza tiene que acercarse a los distintos temas que reclaman su atención desde el amateurismo, como queda claro en este pasaje:

El intelectual debería ser hoy un amateur o aficionado, alguien que considera que el hecho de ser un miembro pensante y preocupado de una sociedad lo habilita para plantear cuestiones morales que afectan al fondo mismo de la actividad desarrollada en su seno, incluso de la más técnica y profesionalizada, en la medida en que dicha actividad compromete al propio país, su poder, sus modos de interactuar con sus ciudadanos y con otras sociedades (1996: 90).

Como vemos, el intelectual al que apuntan las reflexiones de Said es alguien a quien nada que pueda tener que ver con los problemas sociales y humanos en general puede resultarle ajeno. $\mathrm{Al}$ actuar como amateur en distintos ámbitos, se arriega a ser considerado un intruso, claro, pero también es posible que aporte una cierta frescura necesaria, pues el aire fresco sólo puede entrar desde afuera, cuando se abre la puerta o la ventana y se termina el hermetismo. Por eso dice Said que el amateur puede «transformar la rutina meramente profesional con que nos comportamos la mayoría de nosotros en algo mucho más vivo y radical» (1996: 90). Salir de la propia especialidad y entrar en otras para mostrar preocupación por los problemas sociales y, a partir de ellos, plantear cuestiones morales. En resumen, esta es la postura que defiende Said frente a las limitaciones de la especialización y el profesionalismo, una postura que plantea como un deber del intelectual, sobre todo por lo que tiene de 
compromiso con ciertos principios básicos (de justicia, de libertad, etc.) que tienen que ser defendidos a toda costa. Este deber es más notorio cuando toca salir en defensa de las múltiples víctimas colaterales de los abusos de poder.Por eso dice Said que el intelectual tiene que ir en el mismo barco que «el débil y no representado» (1996: 39). Teniendo en cuenta estos planteamientos, no es desde luego extraño que en un momento determinado Said compare al intelectual con Robin Hood. Aunque, para evitar cualquier interpretación excesivamente romántica sobre el asunto, en seguida afirma que no se trata tanto de ser un pacificador o un justiciero como de mantener siempre un espíritu crítico bien vivo y una «actitud de constante vigilancia», pues sólo así se puede estar preparado para rechazar «fórmulas fáciles o clisés estereotipados» y mantenerse en guardia frente a las «confirmaciones tranquilizadoras» del poderoso (1996: 40). Una de las innovaciones que presenta Said en «La función pública de los escritores e intelectuales» respecto de lo ya planteado en las conferencias de 1993 tiene que ver con la preocupación por el público al que se dirige el intelectual. En realidad, esta preocupación había asomado ya en uno de los trabajos que configuran El mundo, el texto y el crítico, precisamente el titulado «Swift como intelectual», donde citaba estas palabras de Lewis Coser:

En primer lugar, los intelectuales necesitan un público, un círculo de personas a las que poder dirigirse y que pueda otorgarles reconocimiento. Un público de estas características, por regla general, le proporcionará también recompensas económicas, pero el prestigio o la estima conferidos al intelectual por su público, sus ingresos psíquicos, pueden ser a menudo más importantes para él que su remuneración económica (2004: 112-113).

La separación apuntada por Coser que tanto interesa a Said recuerda a la que luego estableció Bourdieu entre el capital económico y el capital simbólico. El segundo, relacionado con el prestigio, es el capital verdaderamente importante. Y no se gana trabajando para el poder en cualquiera de sus formas, sino ejerciendo noblemente la función del intelectual al servicio de la sociedad en general, asegura Said. De hecho, el trabajo en el que demuestra que Swift merece ser considerado ya un intelectual, por mucho que sea extraño proyectar esta idea antes del siglo XIX, resume perfectamente los rasgos que, para Said, configuran la esencia de la intelectualidad. De entrada, lo primero que hace Said es liberar a Swift del coto privado en el que lo han colocado los especialistas. Para él, la especialización ha convertido el estudio de la obra de Swift en un almacén de tópicos gastados, entre los cuales sobresale el de que, a pesar del compromiso ideológico del autor irlandés con las posiciones de derechas, «su talento literario le otorga un valor especial» (2004: 108). Este tópico desvía la atención hacia el talento literario y excluye cualquier aproximación seria a la cuestión ideológica. Said se da cuenta y reacciona. Detecta un prejuicio y lo analiza con detalle hasta desmontarlo. Lo hace desde fuera de la especialización, es decir, comportándose como intelectual amateur. Y desde esa posición logra ofrecer una imagen de Swift como auténtico intelectual, un escritor «reactivo» que aprovecha la más mínima ocasión para responder «ante situacionees sobre las que trataba de influir o que pretendía transformar» (2004: 110). Ya tenemos, pues, la voluntad de cambiar el mundo. Recordando luego una extensa cita de Oscar Wilde, Said logra dejar en la mente del lector la impresión de que Swift era un agitador de conciencias, como lo han sido siempre los grandes intelectuales. No puede negarse, y no lo hace Said, que Swift estuvo muy cerca del poder y actuó como intelectual orgánico, pero lo que el 
autor palestino quiere destacar es que también fue un intelectual tradicional y, por eso, los principales temas de su obra están relacionados con «la agresión humana o la violencia humana organizada» (2004: 118). Said cree que si nadie antes que él se ha atrevido a formular este tipo de cuestiones es, sencillamente, porque Swift había pasado a ser considerado «propiedad exclusiva de un círculo de académicos» que se habían interesado por diversos aspectos de su obra, pero sin comprender que la vía de acceso principal tenía que partir de «su conciencia como intelectual» (2004: 122). Al aventurarse por esa vía principal, Said se da cuenta de cuál es la técnica que sigue Swift para vehicular su compromiso ideológico y comprende entonces por qué ese compromiso ha pasado desapercibido. Se ha hablado mucho de la ironía de Swift, pero no se ha comprendido su funcionamiento, cree Said. ¿En qué consiste ese funcionamiento? Este es el diagnóstico de Said: «Switf ataca invariablemente lo que personifica.En otras palabras, su técnica es convertirse en lo que ataca, lo cual normalmente no es un mensaje, ni una doctrina política, sino un estilo o un modo de discurso» (2004: 122).

Es decir, a través de esta técnica, Swift puede estar satirizando, utilizando el objeto mismo que quiere satirizar, distintos lenguajes o estilos: el de la autoridad, el de las instituciones, el de los marginados, el de los ociosos, y hasta el de la conversación educada. A través de esta polifonía, por utilizar el concepto de Bajtin, va mostrando qué significa mantener una posición política o moral determinada y consigue, o intenta conseguir, que sus lectores sean conscientes de esto. Los especialistas no lo habían advertido, pero desde la posición de intelectual amateur Said logra con su original aproximación introducir aire fresco en las investigaciones sobre la obra de Swift.

Por otra parte, también logra dar con la clave del éxito de ventas que tuvo el panfleto de Swift La conducta de los aliados. En esencia, la clave era la misma que explica el éxito de sus escritos en The Examiner.Según Said, Swift «escribió deliberadamente para un público muy amplio», y esto implica buscar una escritura ágil y repleta de trucos periodísticos. Esto significa que buscó una audencia que fuera mucho más allá de «sus iguales»y, por lo tanto, ahí tenemos un ejemplo claro de intelectual que sabe que, además del debate y la discusión entre pares, entre colegas, se necesita llegar a un público amplio para obtener un verdadero reconocimiento.

Como veíamos, este es el tema que regresa años después en «La función pública de los escritores e intelectuales», donde Said se pregunta: «Para quién escribe uno?» (2006: 157). Pero lo que en realidad le preocupa es saber no para quién escribe el intelectual, sino a quién le llega su discurso. Ya Sartre había mostrado una gran preocupación por este tema. Consideraba imprescindible que el intelectual lograra llegar al mayor número de gente posible para que su «misión» pudiera ser realizada con éxito y esto, en el siglo XX, significaba procurar un acceso directo a los mass media. Para poder cumplir de un modo eficaz con su compromiso - explica Sartre en «Qu'est-ce que la littérature?»-, el escritor tiene que conseguir que quienes no le leen pero podrían llegar a hacerlo (es decir: los «lectores virtuales»o «lectores en potencia») se conviertan en su «púbico real», y sólo parece posible ya seguir un camino: «recurrir a medios nuevos» (1990: 231-232). Respecto a esos medios nuevos, escribe Sartre: «Existen ya: los norteamericanos lo han decorado con el nombre de mass media; son los 
verdaderos recursos con que contamos para conquistar al público virtual: el periódico, la radio, el cine» (1990: 232).

La conquista de los mass media por parte de los escritores e intelectuales que planteaba Sartre iba a topar a corto plazo con un obstáculo que acabará convirtiéndose en una de las grandes preocupaciones de Said: el control que los poderosos ejercen sobre esos medios. ¿Cómo puede combatir el intelectual a sus antagonistas si estos controlan las plataformas desde las que se los quería atacar? Antes de responder a esta pregunta, Said se plantea la cuestión del público al que llega el discurso del intelectual en la era Internet. Como sabemos, hoy en día la vía online permite llegar a todas partes, a un número antes inimaginable de personas, y esto dificulta que el intelectual pueda saber si habrá o no una cierta afinidad entre él y la gente que va leerlo, y si van a entender realmente lo que ha querido expresar. Antes un intelectual sabía cómo era su público real, pero ahora escribe para un público virtual y, si quiere asegurar la comprensión de su mensaje, tiene que escribir de la forma más clara posible, piensa Said. Aquí parece resonar de nuevo Sartre cuando, al hablar de la conquista de los mass media, decía: «hay que aprender a hablar en imágenes, a traducir las ideas de nuestros libros a esos nuevos lenguajes (1990: 232). Pero Said ve en esa adaptación al medio un peligro: acabar escribiendo en un «estilo que quizá se parezca demasiado al modo de pensar que uno está tratando de desenmascarar y combatir» (2006: 158). Ahí está el desafío: ¿cómo explicar con el mismo lenguaje que utiliza el enemigo (Said siempre habla de «antagonistas») que el enemigo está mintiendo o manipulando y simplificando las cosas porque lo mueven intereses oscuros? El reto es grande, pero Said cree que el intelectual no tiene más remedio que aceptarlo. Por otra parte, la preocupación por llegar a un público en una época en la que los medios de comunicación más importantes están controlados por el poder lleva a Said a plantearse desde dónde puede hablar el intelectual y ser escuchado. En este punto, cree que la colaboración entre intelectuales independientes y comunidades de activistas que disponen de ciertas plataformas para llegar al público es crucial. La invitación a dar una conferencia, a escribir en una revista o en un periódico alternativos, a publicar en Internet, etc., son algunas de esas plataformas que el intelectual puede aprovechar para poner en marcha la maquinaria dialéctica y, así, frente a un argumento de peso, presentar un contraargumento que pese más aún y muestre una alternativa. Esta idea de la dialéctica como arma para la disputa había sido sólo insinuada en las conferencias de 1993, pero luego se convierte en un motivo recurrente.

La colaboración planteada por Said entre el intelectual y comunidades de activistas le lleva a recordar el concepto de «intelectual colectivo» que manejó Bourdieu cuando quiso demostrarque ya no era posible transformar la sociedad con la ayuda de grandes intelectuales independientes y que había que lograr que varios intelectuales participaran en una lucha colectiva uniéndose por una causa común. Aunque no termina de ver que haya una utopía clara por la que luchar, Said aplaude esta idea de Bourdieu por lo que tiene de invitación a una intervención activa. Así que hay que buscar a otras personas y unirse a ellas en defensa de un proyecto común. Esta idea no estaba en las conferencias de 1993, pero cuando Said entra en detalles y explica qué es lo que tiene que hacer el intelectual para defender ese proyecto colectivo, volvemos a reconocer lo que en esas conferencias ya se decía. Por 
ejemplo, estas palabras podrían haber sido pronunciadas en alguna de aquellas conferencias: «La función del intelectual consiste en presentar narraciones alternativas de la historia y otras perspectivas sobre la misma diferentes de las ofrecidas por los litigantes que defienden la memoria oficial y la identidad y la misión nacionales» (2006: 39). Poco después, Said dice que el intelectual tiene que ser un agitador de conciencias, es decir, que no tiene que permitir «que la conciencia mire hacia otro lado y se adormezca» (2006: 169).En 1993 venía a decir esto mismo. Dando una conferencia, escribiendo un libro o un artículo, concediendo entrevistas, es como Said ha intentado ejercer siempre la esencia de la intelectualidad, manteniéndose al margen de la posición de asalariado en algún medio de comunicación y rechazando ser asesor de algún gobierno.Según propia confesión, se ha sentido así actuando como «un amateur en la esfera pública» y gracias a esto ha podido mantener intacta la «libertad incondicional» de su pensamiento (1996: 95-96). Lo prueba el hecho de que, en su momento, tuviera la valentía de denunciar y cuestionar la versión oficial (la de EEUU) sobre la guerra del Golfo contra Irak, por ejemplo. Y también supo levantar la voz para defender siempre que fue necesario a Shalman Rusdhie, el autor de Versos Satánicos, en nombre de la libertad de expresión. Él decía que había que hablar claro al poder $\mathrm{y}$, como vemos, lo hizo tanto para denunciar guerras desproporcionadas e inmorales (sobre todo las denominadas guerras preventivas, esgrimidas en favor de la seguridad nacional) como para proteger a las víctimas de cualquier tipo de discriminación o represión. A esto se le llama predicar con el ejemplo. Por si quedara alguna duda, vale la pena recordar las palabras con las que terminó uno de los capítulos de Representaciones del intelectual. «Decirle la verdad al poder», afirma allí Said, no es un idealismo, sino «sopesar cuidadosamente las alternativas, escoger la correcta, y luego exponerla inteligentemente donde pueda hacer el máximo bien y provocar el cambio adecuado» (1996: 108).

Mucho tiempo antes, Sartre había dicho aquello de que «nosotros no estamos con quienes quieren poseer el mundo, sino con quienes quieren cambiarlo». Said, que valoraba a Sartre como un intelectual universal, supo poner en práctica esa idea de cambiar el mundo, para mejorarlo, alzando su voz cada vez que lo consideró necesario, ya fuera para defender la causa palestina, o para hablar contra el apartheid en alguna universidad sudafricana, o para quejarse de la visión reducida y simplista con la que se hablaba del islam en distintos ámbitos académicos. Allí donde detectaba una injusticia, o la construcción interesada y falsa de un relato, o una simplificación excesiva de la complejidad de un hecho histórico, trataba de hacer escuchar su voz para decir su verdad. Pero no de forma dogmática, pues siempre intentó, como él mismo decía, «conservar un espacio en la mente abierto para la duda» y también para una cierta ironía que, a menudo, podía convertirse en autoironía (1996: 124). Aquí Swift podía servirle de modelo. En definitiva, Said sabía que al intelectual no se le podía exigir una certeza absoluta sobre nada (él mismo reconocía no haber encontrado una solución para el problema palestino) y por eso él sólo le exigía, y se exigía, sentido crítico. Sentido crítico para poder ver las alternativas a la doxa oficial y también, sencillamente, para poder ver. Para poder ver con una cierta claridad. Porque, de lo contrario, se puede estar contribuyendo a mantener por inercia alguna situación 
injusta, pues, como advertía Said, cuando «sirves acríticamente a un dios, todos los demonios se encuentran siempre en el otro lado» (1996: 123).

\section{Referencias bibliográficas}

AyALA, Francisco (1989): Las plumas del fénix. Madrid, Alianza.

BLASCO, Javier (1998): «¿Obreros de la inteligencia o aristócratas del espíritu?: los intelectuales en el fin de siglo», Ínsula, 614 (febrero), pp. 5-9.

CHOMsKy, Noam (1969): «La responsabilidad de los intelectuales», en La responsabilidad de los intelectuales y otros ensayos históricos y políticos (los nuevos mandarines). Barcelona, Ariel.

FORTANET, Joaquín (2010): «Dos modos de concebir la labor intelectual: Foucault y Rorty», Isegoría (Revista de Filosofía Moral y Política), 42 (enero-junio), pp. 215-229.

GRÜBER, Eduardo (1998): «El retorno de la teoría crítica de la cultura: una introducción alegórica a Jameson y Zizek», en Estudios Culturales. Reflexiones sobre el multiculturalismo. Barcelona, Paidós.

INMAN FOX, E. (1987): «Introducción», en José ORTEGA Y GASSET, Meditaciones sobre la literatura y el arte. Madrid, Castalia.

_ (1998): «El año de 1898 y el origen de los intelectuales», en Ideología y política en las letras de fin de siglo, pp. 13-23.

JAMESON, Frederic (1998): «Sobre los Estudios Culturales», en Estudios Culturales. Reflexiones sobre el multiculturalismo. Barcelona, Paidós.

Reynoso, Carlos (2000): Apogeo y decadencia de los Estudios Culturales. Una visión antropológica. Barcelona, Gedisa.

SAID, Edward (1996): Representaciones del intellectual. Barcelona, Paidós.

- (1996a): Cultura e imperialism. Barcelona, Anagrama.

- (2004): El mundo, el texto y el critic. Madrid, Debate.

- (2006): «La función pública de los escritores e intelectuales», en Humanismo y crítica democratic. Madrid, Debate.

SARTRE, J-P. (1990): Situación, II. Buenos Aires, Losada.

SPIVAK, Gayatri Chakravorty (2009): ¿Pueden hablar los subalternos?. Trad. y ed. crítica de Manuel Asensi. Barcelona, Museu d'Art Contemporani de Barcelona. 